OPEN ACCESS

Edited by: Andrea Gomez-Zavaglia,

Center for Research

and Development in Food

Cryotechnology (Consejo Nacional de Investigaciones Científicas y

Técnicas), Argentina

Reviewed by:

Kenneth James Genovese,

United States Department

of Agriculture, USA

Paul Wigley,

University of Liverpool, UK

*Correspondence.

Agnieszka K. Wyszyńska

agawysz@biol.uw.edu.pl

†These authors have contributed equally to this work.

Specialty section

This article was submitted to

Food Microbiology,

a section of the journal

Frontiers in Microbiology

Received: 04 March 2016 Accepted: 03 May 2016

Published: 19 May 2016

Citation:

KobiereckaPA, WyszyńskaAK,

GubernatorJ, KuczkowskiM,

WiśniewskiO, Maruszewska M, Wojtania A, Derlatka KE, Adamska I,

Godlewska $P$

and Jagusztyn-Krynicka EK (2016)

Chicken Anti-Campylobacter Vaccine - Comparison of Various Carriers and Routes of Immunization.

Front. Microbiol. 7:740

doi: 10.3389/fmicb.2016.00740

\section{Chicken Anti-Campylobacter Vaccine - Comparison of Various Carriers and Routes of Immunization}

\author{
Patrycja A. Kobierecka ${ }^{1 \dagger}$, Agnieszka K. Wyszyńska ${ }^{1 \star \dagger}$, Jerzy Gubernator ${ }^{2}$, \\ Maciej Kuczkowski ${ }^{3}$, Oskar Wiśniewski ${ }^{1}$, Marta Maruszewska', Anna Wojtania ${ }^{1}$, \\ Katarzyna E. Derlatka', Iwona Adamska', Renata Godlewska' ${ }^{1}$ and \\ Elżbieta K. Jagusztyn-Krynicka ${ }^{1}$
}

\footnotetext{
'Department of Bacterial Genetics, Institute of Microbiology, Faculty of Biology, University of Warsaw, Warsaw, Poland, ${ }^{2}$ Department of Lipids and Liposomes, Faculty of Biotechnology, University of Wrocław, Wrocław, Poland, ${ }^{3}$ Department of Epizootiology and Clinic of Birds and Exotic Animals, Faculty of Veterinary Medicine, Wrocław University of Environmental and Life Sciences, Wrocław, Poland, ${ }^{4}$ Department of Animal Physiology, Institute of Zoology, Faculty of Biology, University of Warsaw, Warsaw, Poland
}

Campylobacter spp, especially the species Campylobacter jejuni, are important human enteropathogens responsible for millions of cases of gastro-intestinal disease worldwide every year. C. jejuni is a zoonotic pathogen, and poultry meat that has been contaminated by microorganisms is recognized as a key source of human infections. Although numerous strategies have been developed and experimentally checked to generate chicken vaccines, the results have so far had limited success. In this study, we explored the potential use of non-live carriers of Campylobacter antigen to combat Campylobacter in poultry. First, we assessed the effectiveness of immunization with orally or subcutaneously delivered Gram-positive Enhancer Matrix (GEM) particles carrying two Campylobacter antigens: CjaA and CjaD. These two immunization routes using GEMs as the vector did not protect against Campylobacter colonization. Thus, we next assessed the efficacy of in ovo immunization using various delivery systems: GEM particles and liposomes. The hybrid protein rCjaAD, which is CjaA presenting CjaD epitopes on its surface, was employed as a model antigen. We found that rCjaAD administered in ovo at embryonic development day 18 by both delivery systems resulted in significant levels of protection after challenge with a heterologous $C$. jejuni strain. In practice, in ovo chicken vaccination is used by the poultry industry to protect birds against several viral diseases. Our work showed that this means of delivery is also efficacious with respect to commensal bacteria such as Campylobacter. In this study, we evaluated the protection after one dose of vaccine given in ovo. We speculate that the level of protection may be increased by a post-hatch booster of orally delivered antigens.

Keywords: liposomes, GEM particles, in ovo immunization, rCjaAD, Campylobacter 


\section{INTRODUCTION}

Vaccination is commonly recognized as the most effective strategy to prevent human infectious diseases caused by bacterial and viral pathogens. Several human intestinal diseases, including campylobacteriosis, are zoonoses - human diseases acquired by contact with, or by consumption of, contaminated animal products. Campylobacter jejuni/coli infections are the leading bacterial cause of diarrhoeal illnesses in humans in both developing and developed countries (Kaakoush et al., 2015). Many epidemiological studies indicate that improperly prepared meat from chickens that carry a high load of Campylobacter in their intestinal tracts is the key source of human infections (Hermans et al., 2012; Agunos et al., 2014; Zambrano et al., 2014). The mortality connected with Campylobacter infections is low and campylobacteriosis is largely a self-limiting disease. However, specific treatment is required for patients infected with strains resistant to clinically important antibiotics such as fluoroquinolones and macrolides (Gibreel and Taylor, 2006; Alfredson and Korolik, 2007; Oh and Jeon, 2015) and for patients who develop neurological symptoms or bacteremia due to infection. As the average life span of Europeans steadily increases, one can expect a greater incidence of serious complications from Campylobacter infections, especially in cases affecting older patients. Also, the high social and economic costs of disease cannot be ignored.

While much effort has been made to improve the biosecurity of poultry flocks and hygiene during the processing of poultry products (Katsma et al., 2007; Newell et al., 2011; Wagenaar et al., 2013; Robyn et al., 2015), EFSA data show that since 2005 the level of chicken contamination at farms and the number of reported human campylobacteriosis cases have continued to be high and generally unchanged in many European countries. The number of reported confirmed cases of human campylobacteriosis in the EU in 2013 was 214,779 (EFSA and ECDC, 2015). In 2013, overall, more than 30\% of fresh broiler meat samples tested were Campylobacter positive, although there were large differences among different countries (EFSA and ECDC, 2014). It is estimated that about $30 \%$ of human campylobacteriosis cases in the European Union are associated with consumption or preparation of poultry meat (Wagenaar et al., 2013). Thus, interventions to reduce the level of bird contamination by Campylobacter are greatly needed to help solve an important public health concern and limit the incidence of campylobacteriosis in humans. An efficient chicken vaccine against Campylobacter, suitable for routine use at poultry farms, would solve this public health problem, but this goal has remained out of reach. Chickens are slaughtered at an age of about 6 weeks. Thus, they have to be vaccinated soon after hatching, when their immune system is still immature, and the presented maternal antibodies may block the immune system induction by an administered vaccine prototype (Sahin et al., 2001; Larson et al., 2008; Shoaf-Sweeney et al., 2008).

The choice of an antigen for subunit vaccine generation is a critical step. Significant criteria to consider when searching for potent antigens are the immunogenicity of an antigen, its localization on live bacteria, and its importance in the pathogenhost interaction and virulence. Rapid advances in the global genetic analysis of Campylobacter cells, as well as a deepening understanding of pathogen interactions with eukaryotic cells, has resulted in identification of new antigens that are potentially useful for vaccination (Nielsen et al., 2012; Backert et al., 2013; Hoppe et al., 2014). Numerous Campylobacter extracytoplasmic, conserved proteins have been tested as candidates for vaccine development, with delivery via oral, nasal and parenteral routes. Of these, the most thoroughly examined proteins have been CjaA (solute binding protein; component of the ABC transport system), CjaD (peptidoglycan-binding protein), FlaA (flagellin) and $\mathrm{CmeC}$ (the outer-membrane component of CmeABC multidrug efflux pump). However, the amount of protection obtained varied greatly. The median reduction in C. jejuni cecal contents ranged from $6 \log 10$ to less than $1 \log 10$ (Wyszyńska et al., 2004; Buckley et al., 2010; Zeng et al., 2010; Layton et al., 2011; Clark et al., 2012; Neal-McKinney et al., 2014). While these results are not directly comparable, due to many important experimental design differences, it is generally agreed that surface-located, immunodominant proteins are more potent antigens because they are easily accessible for induced antibodies. Thus, the majority of antigens tested have been extracellular proteins. However, immunization with SodB (superoxide dismutase), which is a cytoplasmic protein, also resulted in a modest reduction of colonization (Chintoan-Uta et al., 2015). In order to overcome problems arising from the genetic diversity of Campylobacter strains and to strengthen immunization efficacy, hybrid proteins such as CjaA presenting $\mathrm{CjaD}$ epitopes on its surface, or recombinant proteins composed of selected parts of surface-exposed colonization proteins (CadFFlaA-FlpA) (named SECPs), have also been assessed (NealMcKinney et al., 2014; Kobierecka et al., 2016). The efficacy of subunit vaccines is determined not only by the antigens in the vaccine but also by the delivery vectors, route and scheme of immunization that are used. So, a wide array of delivery strategies has been examined. Usually recombinant proteins have been delivered via intramuscular or subcutantaneous injection, alone or with an adjuvant. The observed protection, mainly against homologous C. jejuni strain colonization, varied from no reduction to a modest to significant reduction of colonization, and often the protection effect has varied substantially between individual birds (Zeng et al., 2010; Theoret et al., 2012; NealMcKinney et al., 2014). It should also be noted that although a majority of experiments resulted in a significant antibody response, generally there has been no correlation between protection and the induced level of specific IgY (Neal-McKinney et al., 2014; Chintoan-Uta et al., 2015).

As Campylobacter colonizes chicken caeca, it seems that antibody-independent effectors such as mucins or defensins play a role in protection against colonization (van Dijk et al., 2007; Naughton et al., 2013, 2014). However, it cannot be rule out that intestinal sIgA are also important. Thus, several immunogenic proteins have been delivered orally using attenuated Salmonella strains as delivery vehicles (Wyszyńska et al., 2004; Buckley et al., 2010; Layton et al., 2011; Theoret et al., 2012). It should also be noted that oral of vaccination is more feasible to put into 
practice than injections. However, these experiments produced widely varying levels of protection, even when the same antigen was used. The observed discrepancies may come from the varying schemes of immunization, and more likely from the various chicken lines used for experiments and the differences in their gut microbiota (Rubin et al., 2010; Pan and Yu, 2014; Indikova et al., 2015). In addition to attenuated Salmonella strains, an Eimeria strain that produces Campylobacter CjaA protein has been investigated as a delivery vehicle for chicken immunization against two pathogens (Clark et al., 2012). Comparison of the results of immunization using the same antigens delivered in different ways shows the importance of the route of vaccination. Parenteral immunization with hybrid GST-CjaA or Dps (DNAbinding protein from starved cells) resulted in no protection whereas the same antigens administered orally using Salmonella vectors reduced colonization (Wyszyńska et al., 2004; Buckley et al., 2010; Theoret et al., 2012; Chintoan-Uta et al., 2015). In contrast, the subcutaneous delivery route of nanoparticle encapsulated Campylobacter outer membrane proteins provided significant reduction in chicken colonization by Campylobacter, whereas the same preparation administered orally was not effective (Annamalai et al., 2013).

In contrast to many enteropathogens, Campylobacter produces a polysaccharide capsule (CPS). So, it was reasonable to check the efficacy of a conjugated vaccine, even though these kinds of vaccine induce an IgG, not an IgA, immune response. Conjugate vaccines are composed of capsular polysaccharide antigens covalently linked to carrier proteins which enhance the T cell-dependent response (Goldblatt, 2000). They are safe and effective, as was documented in mass routine vaccination against Haemophilus influenzae, Neisseria meningitidis, or Streptococcus pneumoniae (Trotter et al., 2008; Pace et al., 2009; Weil-Olivier et al., 2012; Davis et al., 2013). Anti-Campylobacter immunization with conjugated vaccines (CPS conjugated to CRM197; diphtheria toxoid) have been tested in mice, in an Aotus nancymaae monkey model (Guerry et al., 2012; Maue et al., 2014), and recently, also, as a chicken vaccine prototype. The induction of the bird's immune system was dependent on the chicken immune status (SPF chicks vs. commercial broiler chicks), and a modest protection effect was observed in the case of subcutaneously immunized commercial broilers (Hodgins et al., 2015). The Campylobacter protein $N$-glycosylation pathway has been recently characterized in detail (Szymanski and Wren, 2005). All genes involved in the polysaccharide capsule synthesis and its transfer to the cell surface have recently been transferred to Escherichia coli. This cleared the way for a new technology, termed protein-glycan coupling technology (PGCT), that promises to facilitate conjugate vaccine generation that is lower cost and more repeatable than the current chemical coupling strategy (Ihssen et al., 2010; Terra et al., 2012; Cuccui et al., 2013).

So far, only limited attempts have been undertaken to explore the efficacy of non-live carriers of Campylobacter antigens to prevent bird colonization by Campylobacter. Intranasal immunization of chickens with chitosan-DNA nanoparticles, which carry the recombinant eukaryotic expression plasmid pCAGGS that encodes the major structural subunit of flagella,
FlaA, resulted in modest protection against colonization (Huang et al., 2010). Also, as mentioned above, subcutaneous delivery of nanoparticle encapsulated Campylobacter outer membrane proteins provided significant reduction in chicken colonization by Campylobacter (Annamalai et al., 2013).

The aim of this study was to compare the efficacy of chicken vaccination against Campylobacter with non-live carriers of Campylobacter antigens using various means of vaccine prototype administration. We evaluated the induced immune responses and the reduction of Campylobacter load in bird digestive tracts after immunization with GEM particles and liposomes used as delivery vectors for two Campylobacter immunogenic proteins $(\mathrm{CjaA}$ and $\mathrm{CjaD}$ used together, or the chimeric $\mathrm{rCjaAD})$.

\section{MATERIALS AND METHODS}

\section{Bacterial Strains, Plasmids, Media and Growth Conditions}

Bacterial strains and plasmids used in this study are listed in Table 1. The Lactobacillus salivarius IBB3154 strain used in this study was cultured in MRS-liquid or MRS-agar (solidified with $1.5 \%$ agar) medium (Difco Laboratories, Detroit, MI, USA) at $37^{\circ} \mathrm{C}$ (Kobierecka et al., 2015). The E. coli strain TG1 was used as a host for the construction of recombinant plasmids. The E. coli strain Rosetta (DE3) pLysS was used to overexpress pUWM1414, pUWM1293 and pUWM1313, and E. coli strain BL21 (DE3) was used to overexpress pUWM1282 (Eaniewski et al., 2014). C. jejuni and E. coli strains were grown under standard conditions (Eaniewski et al., 2014) unless otherwise indicated. When needed, media were supplemented with antibiotics at the following concentrations: $30 \mu \mathrm{g} \mathrm{ml}^{-1}$ kanamycin and $15 \mu \mathrm{g} \mathrm{ml}^{-1}$ chloramphenicol, Campylobacter Selective Supplement (Oxoid) and IPTG $\left(3 \mathrm{mg} \mathrm{ml}^{-1}\right)$ in DMF (dimethyl-formamide).

The 1,2-Dipalmitoyl-sn-glycero-phosphatidylcholine (DPPC), 1,2-Distearoyl-sn-glycero-phosphoethanolamine- $N$-[poly(ethylene glycol)2000] (DSPE-PEG 2000) and cholesterol (Chol) were purchased from Northern Lipids, Inc. (Vancouver, BC, Canada). Sephadex G-50 fine was obtained from Sigma-Aldrich Chemie $\mathrm{GmbH}$ (Steinheim, Germany). All the other reagents were of analytical grade.

\section{General DNA Manipulations}

Standard DNA manipulations were carried out as described earlier by Sambrook and Russel (2001) or according to the manufacturer's instructions (A\&A Biotechnology, Poland). DNA sequencing for cloning experiments was performed by Genomed S.A., Warsaw, Poland.

\section{Construction of Recombinant Plasmids for Recombinant Protein Overexpression}

The LysM expression vector was constructed as follows. The LysM coding sequence was cloned from pUWM1287 to pET28b using BamHI and XhoI restriction enzymes, generating 
TABLE 1 | Bacterial strains and plasmids used in this study.

\begin{tabular}{|c|c|c|}
\hline Strain or plasmid & Relevant phenotype(s) or genotype(s) & Source or reference(s) \\
\hline \multicolumn{3}{|l|}{ Strains } \\
\hline E. coli TG1 & supE thi-1 $\Delta$ (lac-proAB) $\Delta(m c r B-h s d S M) 5\left(r K^{-} m K^{-}\right) \mathrm{F}^{\prime}$ [traD36 proAB + lacla lacZ_M15] & Sambrook and Russel, 2001 \\
\hline E. coli Rosetta pLysS (DE3) & $\mathrm{F}^{-}$ompt hsd $\mathrm{S}_{\mathrm{B}}\left(\mathrm{r}_{\mathrm{B}}^{-} \mathrm{m}_{\mathrm{B}}^{-}\right)$gal dcm (DE3) pLysSRARE $\left(\mathrm{Cm}^{\mathrm{R}}\right)$ & Novagen \\
\hline L. salivarius IBB3154 & Isolated from chickens & Kobierecka et al., 2015 \\
\hline C. jejuni $12 / 2$ & Wild type; isolated from a chicken; good colonizer; pUOA18 $\left(\mathrm{Cm}^{R}\right)$ & Wyszyńska et al., 2004 \\
\hline \multicolumn{3}{|l|}{ Plasmids } \\
\hline pGEM-T Easy & $A p^{R} ; T$ vector for cloning PCR products & Promega \\
\hline pET28a & $\mathrm{Km}^{\mathrm{R}}$; lacl; overexpression vector & Novagen \\
\hline pET22 & $A p^{R}$; lacl; overexpression vector & Novagen \\
\hline pBluescript II SK & $A p^{R} ;$ general cloning vector & Stratagene \\
\hline pUWM1287 & Source of fragment DNA encoding motif lysM L. lactis IL1413 & This work \\
\hline pUWM1293 & 6xhis-lysM fusion in pET28b & This work \\
\hline pUWM1312 & 6xhis-cjaA-lysM fusion in pET28a & Kobierecka et al., 2015 \\
\hline pUWM1282 & 6xhis-cjaD-lysM fusion in pET28a & Kobierecka et al., 2015 \\
\hline pUWM1379 & 6xhis-rcjaAD-6xhis fusion in pET28a & Kobierecka et al., 2016 \\
\hline pUWM1414 & 6xhis-rcjaAD-lysM fusion in pET28a & This work \\
\hline
\end{tabular}

pUWM1293. Construction of the CjaA-LysM and CjaD-LysM expression vectors (pUWM1312 and pUWM1282, respectively) was described previously (Kobierecka et al., 2015). An rCjaADLysM expression vector was constructed as follows. The plasmid pUWM1293, was digested with XhoI and BamHI restriction enzymes and a $0.75 \mathrm{~kb}$ DNA fragment coding LysM was inserted into pUWM1379, generating plasmid pUWM1414 (Kobierecka et al., 2016).

Correct construction of the plasmids was verified by sequencing. Protein production was confirmed by a Western blot using previously obtained rabbit polyclonal anti-CjaD, anti-CjaA (Pawelec et al., 2000; Łaniewski et al., 2012) and rabbit polyclonal anti-LysM serum. All the recombinant plasmids encode proteins with a $6 \mathrm{His}$ tag fused to their $\mathrm{N}$-terminus to allow purification by affinity chromatography.

\section{Protein Work Overexpression and Purification of LysM, CjaALysM, CjaDLysM, rCjaADLysM, rCjaAD}

CjaDLysM, CjaALysM, rCjaAD were overexpressed and purified as described previously (Kobierecka et al., 2015, 2016). The protein rCjaADLysM was overexpressed from an E. coli Rosetta (DE3) pLysS strain harboring pUWM1414, using autoinduction as described by Studier (2005). After $24 \mathrm{~h}$, cultures were centrifuged and the cell pellets were suspended in $50 \mathrm{mM}$ sodium phosphate, $\mathrm{pH} 8.0,300 \mathrm{mM} \mathrm{NaCl}, 10 \mathrm{mM}$ imidazole with $10 \mathrm{mg} \mathrm{ml}^{-1}$ lysozyme and $1 \mathrm{mM}$ PMSF. Cells were disrupted by sonication. Subsequently, the cell lysates were centrifuged and the resulting supernatants were applied onto a HisTrap column (Novagen). The proteins were eluted with an imidazole gradient. LysM was overexpressed and purified from E. coli Rosetta (DE3) pLysS harboring pUWM1293. Expression of LysM was induced with $0.5 \mathrm{mM}$ IPTG at $\mathrm{OD}_{600 \mathrm{~nm}} \sim 0.6$ from cells growing at $18^{\circ} \mathrm{C}$. After $24 \mathrm{~h}$, the culture was centrifuged and the cell pellet was suspended in Cell Lysis Buffer I (50 mM Tris-HCl; pH 8.0, $1 \mathrm{mM}$ EDTA, $100 \mathrm{mM} \mathrm{NaCl}$ ) with $0.2 \mathrm{mg} \mathrm{ml}^{-1}$ lysozyme and $0.1 \mathrm{mM}$ PMSF. After $30 \mathrm{~min}$ of incubation, deoxycholic acid was added. Purification and washing of inclusion bodies was done using Triton X-100. The pellet was suspended in Cell Lysis Buffer II (50 mM Tris-HCl; pH 8.0, 10 mM EDTA, $100 \mathrm{mM} \mathrm{NaCl}, 0.5 \%(\mathrm{v} / \mathrm{v})$ Triton X-100) at a 1:9 ratio. After 5 min incubation, the suspension was centrifuged and pellet was suspended in Inclusion-body Solubilization Buffer I (50 mM Tris-HCl; pH 8.0, 1 mM EDTA, $100 \mathrm{mM} \mathrm{NaCl,} 8 \mathrm{M}$ urea, $0.1 \mathrm{mM}$ PMSF). After $1 \mathrm{~h}$, Inclusion-body Solubilization Buffer II was added at a 1:9 ratio. The $\mathrm{pH}$ was readjusted to 10.7 using $10 \mathrm{~N} \mathrm{KOH}$. After $30 \mathrm{~min}$, the $\mathrm{pH}$ of the solution was adjusted to eight using $12 \mathrm{~N} \mathrm{HCl}$. After $30 \mathrm{~min}$ suspension was centrifuged and the pellet was resuspended in Buffer $\mathrm{B}$ (100 mM sodium phosphate, $10 \mathrm{mM}$ Tris- $\mathrm{HCl}, 8 \mathrm{M}$ urea, $\mathrm{pH}$ 8.0) and then sonicated. Subsequently, the lysate was centrifuged and the resulting supernatant was applied onto a HisTrap column (Novagen). The proteins were eluted with decreasing $\mathrm{pH}$.

Fractions containing CjaDLysM, CjaALysM, rCjaADLysM, LysM were pooled and extensively dialyzed against phosphate buffered saline (PBS). Overexpression and all purification steps were monitored by SDS-PAGE.

LysM was used for rabbit immunization. Rabbit immunization was carried out according to the ethical standards and with the approval (No. 448/2013) of the Local Ethics Committee No. 1, Warsaw, Poland.

The anti-LysM rabbit serum was specific and recognized LysM protein, as verified by Western blot analysis.

\section{SDS-PAGE and Western blotting}

SDS-PAGE and Western blotting procedures were done by standard techniques. Blots were developed with nitro blue tetrazolium chloride/5-bromo-4-chloro-3-indolyl phosphate (Sigma-Aldrich) as a substrate, using previously obtained rabbit 
polyclonal anti-CjaA, anti-CjaD, anti-rCjaAD (Pawelec et al., 2000; Łaniewski et al., 2012), or anti-LysM (this work) sera as primary antibodies, and mouse anti-rabbit $\operatorname{IgG}$ alkaline phosphatase conjugate (Sigma-Aldrich) as secondary antibodies.

\section{Assessment of the Immune Responses and Chicken Protection Preparation of GEM Particles}

GEM particles were obtained by chemical pre-treatment L. salivarius IBB3154 with $10 \%$ trichloroacetic acid (TCA) as described previously (Kobierecka et al., 2015). Briefly, bacterial cells from culture with an absorbance of about 1.0 at $\mathrm{OD}_{600 \mathrm{~nm}}$ were collected by centrifugation and washed with phosphatebuffered saline (PBS). Next, the washed cells were resuspended in 10\% TCA solution and boiled for $30 \mathrm{~min}$ (Bosma et al., 2006). Then, the GEM particles were washed three times with PBS. For protein binding, the prepared GEM particles were resuspended in MRS. Then $2.5 \times 10^{9}$ of GEM particles were mixed with $2000 \mathrm{pmol}$ of recombinant proteins (I. 1000 pmol CjaALysM and 1000 pmol CjaDLysM; II. 2000 pmol rCjaADLysM), incubated for $60 \mathrm{~min}$, and then washed three times with PBS.

\section{Preparation of Liposomes Containing rCjaAD Protein}

DPPC/Chol/DSPE-PEG 2000 (5.8:4:0.2 mol/mol) liposomes were prepared using the dehydration and hydration method followed by an extrusion protocol. Briefly, $90 \mathrm{mg}$ of lipids were dissolved in $4 \mathrm{ml}$ of cyclohexane with $100 \mu \mathrm{l}$ of methanol and frozen in liquid nitrogen. The sample was then freeze-dried overnight at low pressure using a Savant Modulyo apparatus (Savant, USA). Multilamellar vesicles (MLVs) were formed by hydrating the lipid film in $2.8 \mathrm{ml}$ of deionized water, at $50^{\circ} \mathrm{C}$. Large unilamellar vesicles (LUVs) were prepared by extrusion through Nucleopore polycarbonate filters with a pore size of $100 \mathrm{~nm}$ (five passes) on a Thermobarrel Extruder (Lipex Biomembranes, Vancouver, BC, Canada). The extruder was equilibrated to a temperature of $50^{\circ} \mathrm{C}$ prior to liposome extrusion. The mean diameter of the vesicles was determined (multimodal analysis, volume weighted) using a Zetasizer Nano-ZS (Malvern Instruments Ltd., Malvern, UK). They were generally in the size range $110-120 \mathrm{~nm}$. Then, $2 \mathrm{ml}$ of liposomal suspension was mixed with $1000 \mu \mathrm{l}$ of the $\mathrm{rCjaAD}$ protein solution $\left(10 \mathrm{mg} \mathrm{ml}^{-1}\right)$. The sample was then freeze-dried overnight at low pressure using the Savant Modulyo apparatus, and the resulting lipid/protein powder was suspended in $1 \mathrm{ml}$ of deionized water at $50^{\circ} \mathrm{C}$ and extruded through a $400 \mathrm{~nm}$ pore filter (five passes) as described above. The size of liposomes was usually in the range of $350-365 \mathrm{~nm}$.

\section{Determination of Protein Incorporation Efficiency (IE)}

Non-encapsulated protein was removed from the rCjaADcontaining liposomes by size exclusion chromatography on a Sephadex G-50 mini-column $(10 \times 150 \mathrm{~mm})$ equilibrated with $150 \mathrm{mM} \mathrm{NaCl}$ solution. The concentration of the protein was assessed by the use of modified Laurie protocol. A $30 \mu 1$ liposome suspension was mixed with $70 \mu \mathrm{l}$ of deionized water, followed by addition of $500 \mu \mathrm{l} \mathrm{A/B}$ solution mixture (50:1), and then $100 \mu \mathrm{l}$ of the $2 x$ diluted Folin-Ciocaltau reagent. Next, $60 \mu$ l of the $10 \%$ Triton X-100 solution was mixed with the sample and the sample was heated to $60^{\circ} \mathrm{C}$ for $30 \mathrm{~s}$. and then cooled immediately in water (room temperature). The absorbance of the samples after $30 \mathrm{~min}$ incubation was read at $778 \mathrm{~nm}$ (Shimadzu UV 2401 PC spectrophotometer, Shimadzu, Japan) and the amount of protein was calculated from a previously prepared standard curve for the pure protein $(5-50 \mu \mathrm{g})$. The incorporation efficiency (IE) was calculated as the percentage of $\mathrm{rCjaAD}$ protein remaining with the liposomes following elution, for the normalized lipid concentration. Lipid concentration was assessed by the modified Stewart method (Stewart, 1980).

\section{Immunization and Challenge Regimens}

All animal experiments were carried out according to the ethical standards and with the approval (No. 397/2012 and No. 516/2013) of the Local Ethics Committee No. 1, Warsaw, Poland. Chickens were confirmed to be culture-negative for Campylobacter by cloacal swabbing.

\section{Per os and Subcutaneous Immunization}

Hy-line chickens were obtained on the day of hatch from a local hatchery. Birds were randomly assigned to experimental groups and housed in an animal facility in separate cages for each group. Experiments were performed on chickens hatched and reared under controlled conditions from the day of hatch. The chickens were kept under controlled light (L:D 12:12) and temperature $\left(32 \pm 2^{\circ} \mathrm{C}\right.$ during first week and $24 \pm 2^{\circ} \mathrm{C}$ thereafter) conditions, with free access to the standard food and water.

Chickens deprived of food and water for $4 \mathrm{~h}$ were orally or subcutaneously inoculated with $2.5 \times 10^{9} \mathrm{CFU}$ of $L$. salivarius GEM particles with CjaALysM and CjaDLysM presenting on their surface. Booster doses were administrated 9 and 19 days after primary immunization. Following vaccination, chickens were observed for development of diarrhea and other potential adverse side effects. A group of birds inoculated with BSG was used as control. At the 30th day of life, birds were orally challenged with $\sim 10^{4} \mathrm{CFU}$ of $C$. jejuni 12/2. At 5 and 10 days post-challenge, 5-7 birds from each group were euthanized and samples of cecum were collected. Dilutions of the contents were made in PBS and plated onto BA plates supplemented with 5\% horse blood, "Campylobacter Selective Supplement (BlaserWang)" and chloramphenicol $\left(15 \mu \mathrm{g} \mathrm{ml}^{-1}\right)$ for enumeration of C. jejuni. Plates were incubated at $37^{\circ} \mathrm{C}$ for $48 \mathrm{~h}$. Plates that were culture-negative at $48 \mathrm{~h}$ were reincubated for an additional $48 \mathrm{~h}$. This procedure permits detection of $10^{3} \mathrm{CFU} / \mathrm{g}$ of cecal contents.

\section{In Ovo Immunization}

Animal experiments were performed using the Rosa 1 breed of chickens. This breed was created by crossing a Sussex hen with a Rhode Island Red rooster. Eighteen-day-old embryonic chicken eggs obtained from a local hatchery were inoculated with GEM particles or liposomes. Birds inoculated with PBS were used as a control group. Using a needle, $0.1 \mathrm{ml}$ of inoculum was injected into the amniotic fluid. Hatched chickens of each group were placed in separate cages and provided with ad libitum food and water during the experimental period. 
At 2 weeks of age, birds were orally challenged with $\sim 10^{6}$ $\mathrm{CFU}$ of C. jejuni strain 12/2. At weeks 1 and 2 post-challenge, 6 birds (from each group) were euthanized and samples of cecum were collected. Dilutions of the contents were made in PBS and plated onto BA plates supplemented with 5\% horse blood, "Campylobacter Selective Supplement (Blaser-Wang)" and chloramphenicol $\left(15 \mu \mathrm{g} \mathrm{ml}^{-1}\right)$ for enumeration of C. jejuni. Plates were incubated at $37^{\circ} \mathrm{C}$ for $48 \mathrm{~h}$. Plates that were culturenegative at $48 \mathrm{~h}$ were reincubated for an additional $48 \mathrm{~h}$. This procedure permits detection of $10^{3} \mathrm{CFU} / \mathrm{g}$ of cecal contents.

Additionally, to monitor the humoral immune response, six birds from each group were sacrificed on days $7,14,21$, and 28 post-hatch and samples of gut secretion were collected for the post-mortem examination. Secretory IgA antibodies were extracted from lower parts of the intestine with PBS containing $0.05 \%$ Tween 20 and soybean trypsin inhibitor $\left(0.1 \mathrm{mg} \mathrm{ml}^{-1}\right)$ (dilution $1: 10$ ). Samples were shaken for $2 \mathrm{~h}$ at $4^{\circ} \mathrm{C}$, centrifuged at $20,000 \times g$ for $30 \mathrm{~min}$ at $4^{\circ} \mathrm{C}$, and afterward the supernatant was collected and stored at $-20^{\circ} \mathrm{C}$.

\section{Enzyme-Linked Immunosorbent Assay (ELISA)}

The 6xHis-tagged rCjaAD protein purified as described above was also used as a coating antigen. The levels of antibody against rCjaAD protein in chicken intestinal secretions were quantified by ELISA. Briefly, 96-well Maxisorp plates (Nunc, Rochester, NY, USA) were coated with purified $\mathrm{rCjaAD}$ protein $(5 \mu \mathrm{g}$ per well) in PBS and incubated overnight at $4^{\circ} \mathrm{C}$. Then, plates were blocked for $1 \mathrm{~h}$ at $37^{\circ} \mathrm{C}$ with PBS containing $0.1 \%$ Tween 20 (Sigma-Aldrich) and 1\% bovine serum albumin (BSA), washed three times with PBS containing 0.1\% Tween 20 (Sigma-Aldrich) and incubated for $1 \mathrm{~h}$ at room temperature with the intestinal secretion samples (1:10). Goat anti-chicken IgA horseradish peroxidase conjugate (Thermo Fisher, Scientific) was employed to detect chicken IgA that bound to Campylobacter antigens. The plates were developed with 3,3',5,5'-tetramethylbenzidine (Sigma-Aldrich), according to the manufacturer's directions. The reaction was stopped with $3 \mathrm{M} \mathrm{H}_{2} \mathrm{SO}_{4}$ and optical density was determined at $A 490$ using an ELISA reader (Tekan). Each sample was analyzed in triplicate.

\section{Statistical Analysis}

Statistical analyses of the colonization results and ELISA test were performed using STATISTICA 10PL software (StatSoft, USA). The significance of differences between the obtained values was appraised using the Kruskal-Wallis test. Any $p$-values $<0.05$ were considered significant.

\section{RESULTS}

\section{Oral and Subcutaneous Immunization with GEM Particles Presenting CjaA and CjaD Proteins - Protection Analysis}

Two highly immunogenic, extracytoplasmic and conserved C. jejuni proteins - CjaA (Cj0982c in the genome of C. jejuni
NCTC11168) and CjaD (Cj0113 in the genome of C. jejuni NCTC11168), which are often tested as candidates for chicken anti-Campylobacter vaccination - were chosen for this study. The immunogenicity of $\mathrm{CjaA}$ and $\mathrm{CjaD}$ has been documented by our research group, as well as by others (Wyszyńska et al., 2004; Buckley et al., 2010; Layton et al., 2011; Clark et al., 2012; Hoppe et al., 2012). Recently we have shown that GEM particles (Gram-positive Enhancer Matrix), from TCA-pretreated L. salivarius, can act as a surface display platform for C. jejuni antigens (Bosma et al., 2006; Kobierecka et al., 2015). In this study we tested the efficacy of chicken immunization with GEMs presenting $\mathrm{CjaA}$ and $\mathrm{CjaD}$, using two routes of vaccine administration. Both proteins, fused with the PA binding domain of the L. lactis peptidoglycan hydrolase, AcmA, that contains three lysine motifs (LysM), were obtained using an E. coli expression system and were purified by affinity chromatography. Both chimeras reacted with specific rabbit anti-LysM serum (Supplementary Figure S1). Chimeras were bound to GEM particles as described previously (Kobierecka et al., 2015). The binding efficiency was determined by Western blot analysis using specific rabbit anti-CjaA and anti-CjaD sera (data not shown). First, we examined whether oral or subcutaneous immunization resulted in reduction of the Campylobacter load in bird intestinal tracts. For oral immunization, 1-day old chickens were immunized with GEM particles presenting CjaA and CjaD. A groups of birds inoculated with BSG or GEM particles were used as control (details are given in the Section "Materials and Methods").

Chickens were boosted with the same doses of identical GEM particles at 9 and 19 days post-hatch and were orally challenged with $\sim 10^{4}$ CFU of $C$. jejuni wild-type strain $12 / 2$ at the 30 th day of life. The level of colonization was evaluated at 5 and 10 days post challenge (Figure 1A). For subcutaneous immunization, the same scheme was applied (Figure 1B). We found that neither the oral nor the subcutaneous route of vaccination resulted in a protective effect against bird intestinal tract colonization by wild type C. jejuni strain.

\section{In Ovo Immunization Using GEM Particles and Liposomes as Vectors for Campylobacter Antigens}

In ovo chicken vaccination has been a common practice in the poultry industry for many years to protect birds, mainly against viral diseases such as Marek's disease, infectious bursal disease or Newcastle disease (Negash et al., 2004). Given that chickens develop certain immunologic functions before hatching, we decided to evaluate the efficacy of in ovo chicken immunization against C. jejuni with two non-live carriers of Campylobacter antigens: GEM particles and neutral liposomes. To the best of our knowledge, liposomes, which have been studied as a delivery system for many vaccine formulations, have so far not been tested for in ovo chicken immunization. Instead of employing the two separate antigens, $\mathrm{CjaA}$ and $\mathrm{CjaD}$, we used the recently generated hybrid protein $\mathrm{rCjaAD}$ for the immunizations with either GEM particles or liposomes as carriers. rCjaAD is a $\mathrm{CjaA}$ that presents three selected $\mathrm{CjaD}$ epitopes on its 


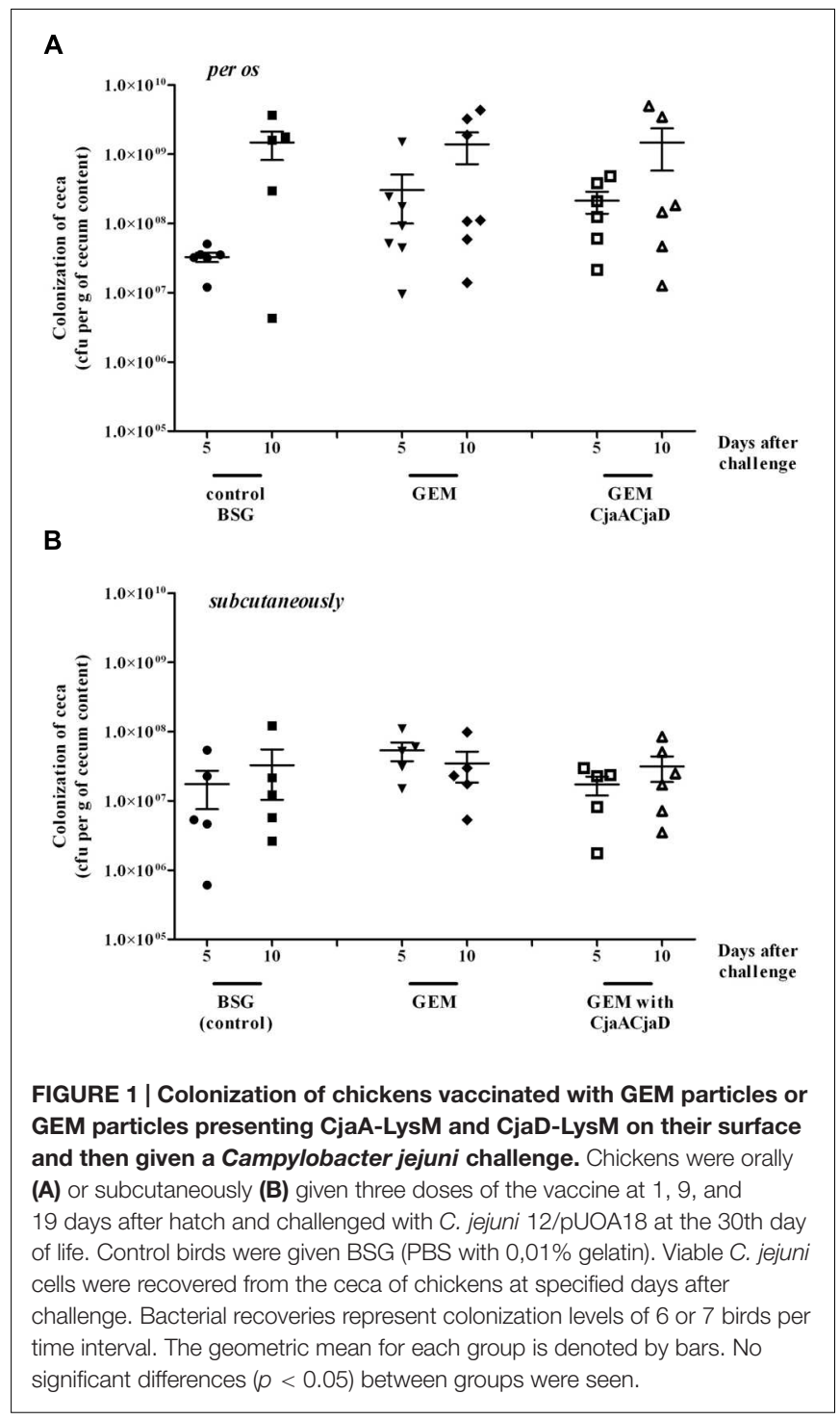

surface. It has been shown the specific antibodies obtained by rabbit immunization with $\mathrm{rCjaAD}$ recognize both of the native CjaA and CjaD proteins produced by wild type Campylobacter (Kobierecka et al., 2016).

\section{Characterization of the GEMs-rCjaAD Complexes}

To ensure its binding to GEMs, rCjaAD was fused to the PA binding domain of the L. lactis peptidoglican hydrolase, AcmA, which contains LysM motifs (Bosma et al., 2006). The rCjaAD-LysM chimera, additionally equipped with a 6His tag, was obtained using an E. coli expression system and affinity chromatography purification. Its proper conformation was confirmed by Western blot analysis using specific rabbit anti-CjaA, anti-CjaD and anti-LysM antibodies (Supplementary Figure S2). rCjaAD was bound to the surface of GEMs particles as described previously (Kobierecka et al., 2015). The binding efficiency was determined by Western blot analysis using specific rabbit anti-CjaA and anti-CjaD sera (data not shown) and by immunofluorescence (Supplementary Figure S3).

\section{Characterization of Liposome-rCjaAD Complexes}

The $\mathrm{rCjaAD}$ protein employed in this experiment was obtained as described above using an E. coli expression system and affinity chromatography purification. After addition of the protein solution to the unilamellar liposome suspension, the mixture immediately became less transparent, with no essential liposomes size increase, suggesting a strong protein bilayer interaction and protein incorporation into the bilayer. Measurement of protein incorporation efficiencies supports this presumption because, despite the protein incorporation method (data not shown), this parameter varied only from 96 to $98 \%$, indicating that the protein is incorporated into the bilayer, not encapsulated within the liposome aqueous interior. Such protein localization in the neutral liposomes further facilitates liposome/proteincell interactions. Attempts to use cationic liposomes instead of neutral ones (data not shown), which contained 20\% cationic lipid (DOTAP), resulted in strong electrostatic complex formation between large unilamellar liposomes $(110 \mathrm{~nm})$ and $\mathrm{rCjaAD}$ protein, leading to liposome aggregation and fusion. Attempts to decrease the size of the aggregated liposomes was not successful, either by extrusion or mild sonication (liposomes stacked on the polycarbonate filter during extrusion).

\section{Chicken Immunization In Ovo}

Two groups of 18-day-old embryonated chicken eggs were immunized with GEM particles or liposomes carrying Campylobacter antigen. A group of birds inoculated with PBS was used as a control. The details of the immunization procedure are given in materials and methods section. The protective effect of in ovo vaccination was assessed by a plating method after oral challenge with $1 \times 10^{6}$ bacterial cells of a broiler-isolated C. jejuni strain. The C. jejuni strain used for the challenge experiment was labeled with the pUOA18 plasmid containing a cat gene.

We found that both GEMs particles and liposomes with rCjaAD reduced the level of birds' caeca colonization by wild type Campylobacter as compared to the control group (Figure 2). The mean CFU/gram of cecal content observed in the group that received GEMs presenting $\mathrm{CCjaAD}$ was about $1 \times 10^{9}$, whereas the mean level of colonization in the control group was $\sim 1 \times 10^{10}$ $\mathrm{CFU} /$ gram. The protective effect was even more significant for the group immunized with $\mathrm{rCjaAD}$ delivered by liposomes. The mean CFU/gram of cecal content observed after 2 weeks in the group that received liposomes containing $\mathrm{rCjaAD}$ was about $2 \times 10^{7}$. And, importantly, three out of six chickens were colonized below detection level $\left(10^{3} \mathrm{CFU} / \mathrm{g}\right.$ of cecal contents).

The level of the specific intestinal IgA against $\mathrm{rCjaAD}$ was measured for chickens at days 7, 14, 21, and 28 post-hatch. The data show that in ovo immunization stimulated the gutassociated immune system, and the effect was more marked for vaccination using liposomes as the delivery vector (Figure 3). The high response observed in the control group (14 days after hatch) 


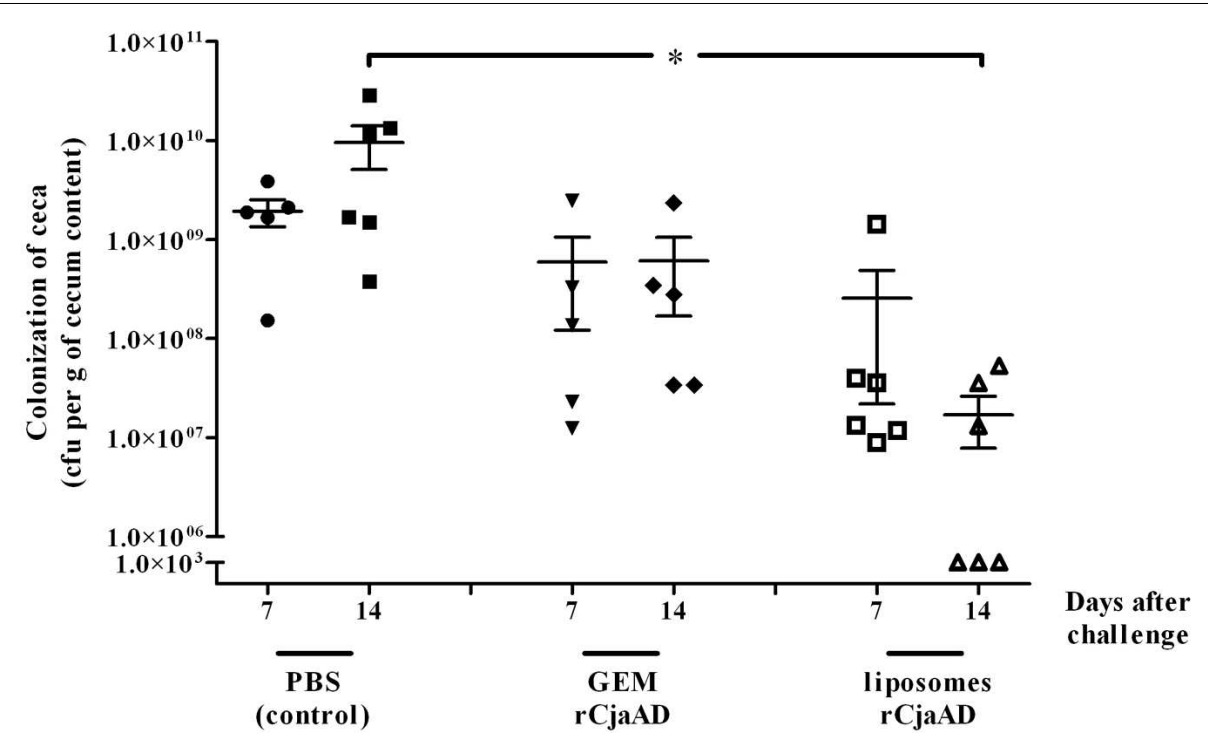

FIGURE 2 | Colonization of chickens vaccinated in ovo with: GEM particles presenting rCjaAD-LysM on their surface or liposomes containing rCjaAD, and then given a C. jejuni challenge. 18-day-old embryonated chicken eggs were inoculated with $0.1 \mathrm{ml}$ GEM particles or liposomes and challenged with C. jejuni /pUOA18 on day 14 of life. Control birds were given PBS. Viable C. jejuni cells were recovered from the ceca of chickens 7 and 14 days after challenge. Bacterial recoveries represent colonization levels of 5 or 6 birds per time interval. The geometric mean for each group is denoted by bars. Asterisks indicate significant differences $(p<0.05)$ between analyzed groups and control group.

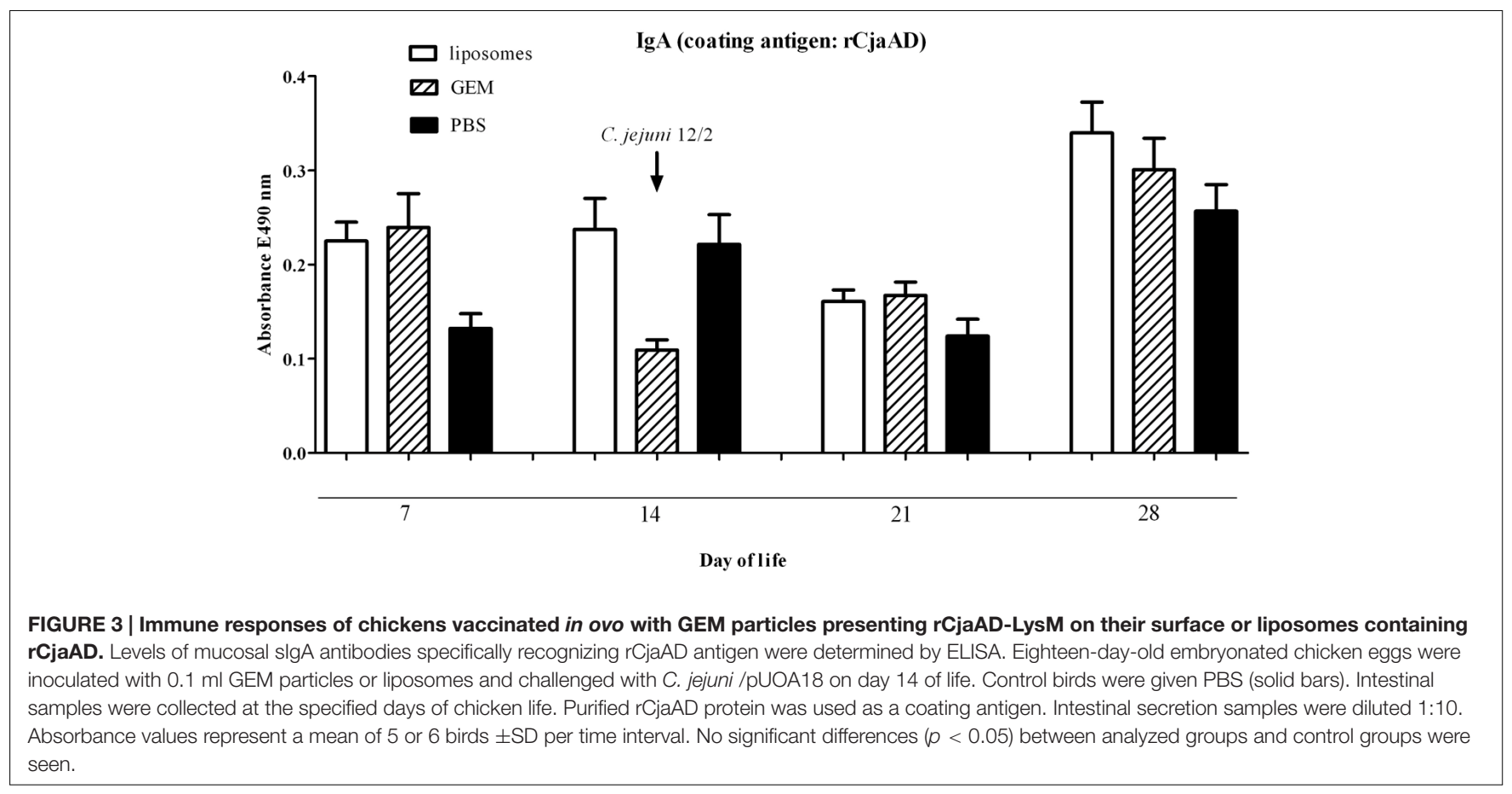

resulted from a high IgA level detected in the intestinal sample of one bird.

The median reduction of C. jejuni cecal contents was $1 \log _{10}$ for in ovo immunization with GEM particles containing rCjaAD and $\sim 2 \log _{10}$ for in ovo immunization with liposomes containing $\mathrm{rCjaAD}$. The efficacy of in ovo immunization with non-live carriers may be increased by booster immunization after hatching with vectors known to induce a mucosal immune response, such as Lactobacillus spp. or attenuated Salmonella strains carrying Campylobacter antigens. Our results provide evidence that in ovo chicken vaccination using appropriate carriers and recombinant antigens may be an efficient way to reduce the level of chicken colonization by Campylobacter and thus reduce the burden of human campylobacteriosis. 


\section{DISCUSSION}

Campylobacteriosis, caused mainly by C. jejuni, is still one of the most common food-borne human illnesses worldwide, and contaminated poultry meat is considered to be the main risk factor of human infections. Various vaccine strategies, including parenteral, oral and nasal routes using different antigens, have recently been evaluated in experimental studies to decrease the level of chicken colonization by the $C$. jejuni pathogen in order to ease this serious health problem. However, knowledge concerning the interaction between $C$. jejuni and its hosts is still limited, and we still do not understand what kind of immune response is needed to combat this pathogen. It is still debatable whether we can consider Campylobacter as a chicken commensal organism since infection of birds does not provoke signs of pathology, but does induce an inflammatory response. Additionally, Campylobacter infection has an impact on bird's intestine functioning by influencing on specific gene expression and by inducing histomorphological changes of epithelium and modulating its barrier function (Awad et al., 2014, 2015a,b). Moreover, the observation that the immune response to infection is dependent on the breed of broiler chicken has led to substantial confusion (Humphrey et al., 2014).

To better understand the chicken immune response and develop an efficient strategy to combat chicken colonization by Campylobacter, this study has evaluated the protective effect of chicken vaccination using non-live vectors (GEM particles and liposomes) harboring Campylobacter antigens delivered by various routes. Two immunogenic Campylobacter antigens (CjaA and $\mathrm{CjaD}$, previously used by us and others in experimental chicken oral vaccination studies), were employed (Wyszyńska et al., 2004; Buckley et al., 2010; Layton et al., 2011). Assuming that GEM particles should be taken up by epithelium M cells and based on the results of rabbit oral mucosal immunization with GEMs presenting Plasmodium falciparum surface antigen MSA2, we tested the efficiency of oral chicken immunization with GEMs presenting C. jejuni antigens (Ramasamy et al., 2006). As several attempts have been also undertaken to immunize chickens against Campylobacter with different protein antigens by a parenteral route of administration, we also used GEMs decorated with $\mathrm{CjaA}$ and $\mathrm{CjaD}$ for subcutaneous vaccination. Chicken immunization with GST-Dps or GST-CjaA proteins combined with adjuvant does not provide protection, whereas immunization with hybrid protein consisting of selected parts of surface-exposed colonization proteins (CadF-FlaA-FlpA; named SECPs) combined with adjuvant resulted in significant protection (Theoret et al., 2012; Neal-McKinney et al., 2014). However, it should be noted that the chickens used in these two experiments differed considerably in their immunological status (1-dayold chicks vs. specific-pathogen-free chicks). GEM particles are mainly composed of cell wall peptidoglycan. Given that peptidoglycan is a known ligand of TLR2 receptors, it should act as an immunostimulator of the innate immune system (Keestra et al., 2013). Thus, the subcutaneous immunization using GEMs that present $\mathrm{CjaA}$ and $\mathrm{CjaD}$ was not combined with extra adjuvant. Neither oral nor subcutaneous vaccination with GEMs presenting $\mathrm{CjaA}$ and $\mathrm{CjaD}$ resulted in chicken protection against Campylobacter, even though the same antigens administered by the oral route, using attenuated Salmonella as a delivery vector, produced modest or even high levels of protection (Wyszyńska et al., 2004; Buckley et al., 2010; Layton et al., 2011). It is likely that, in the case of oral immunization, both antigens displayed on the surface of GEM particles were degraded in the bird gut, so only small amount of antigens were processed by the intestinal APC cells. The chicken lines used in experiments need to be scrutinized because significant genetic differences among them, as well as differences in their gastrointestinal microbiota conditioned by diet, may significantly influence the immune responses (Rubin et al., 2010; Yeoman et al., 2012; Pan and Yu, 2014; Schokker et al., 2015). Data from oral chicken vaccination against Campylobacter has indicated that the intestinal mucosal immune response to produce specific sIgA, played a crucial, though not sufficient, role in a bird's protection (Hermans et al., 2014). So far, the chicken cellular response to Campylobacter infection remains undefined (Wigley, 2013). Though Campylobacter had been thought a human pathogen that was incapable of entering intestinal epithelium cells, recent evidence shows that Campylobacter can transmigrate across the gut epithelial barrier, invade epithelial cells from the basolateral side and survive in specific Campylobactercontaining vacuoles (CCV) (Watson and Galan, 2008; Backert et al., 2013; Bouwman et al., 2013). Campylobacter's interaction with the chicken immune system and with chicken intestinal epithelium cells remains poorly understood (Wigley, 2013). Campylobacter can invade primary chicken epithelial cells or chicken hepatocellular epithelial cells, though with low efficiency (LMH) (Byrne et al., 2007; Larson et al., 2008). So the issue whether cellular immune responses may play a role in chick protection against Campylobacter remains elusive.

Chicken in ovo immunization has long been widely used by the poultry industry to prevent viral diseases (Negash et al., 2004). The in ovo route of vaccine administration is easy to use for mass vaccination, and it is more precise and more efficient than post-hatch immunization by spray or drinking water. Many new vaccine formulations are under extensive investigation in order to assess their efficacy in in ovo immunization They include immunization with plasmid DNA, live attenuated viruses or using viral vectors as antigen carriers (Toro et al., 2007; Bande et al., 2015). To the best of our knowledge, the present work is the first to analyze the effect of chicken immunization in ovo with a subunit vaccine prototype against bacterial pathogens. The only experiment to estimate the results of in ovo vaccination against Campylobacter infection was performed 40 years ago with killed, whole bacterial cells. The data presented at that time indicated that in ovo vaccination induced a mucosal immune response (Noor et al., 1995). For our in ovo administration, rather than using two separate antigens, we used the hybrid $\mathrm{rCjaAD}$ protein, which is an engineered $\mathrm{CjaA}$ presenting $\mathrm{CjaD}$ epitopes. As previously shown, antibodies against $\mathrm{rCjaAD}$ recognize both native $\mathrm{CjaA}$, as well as native $\mathrm{CjaD}$, protein, which confirms its usefulness for vaccination (Kobierecka et al., 2015). Experiments are in progress to generate hybrid $\mathrm{CjaA}$ proteins presenting more epitopes originating from other conserved immunogenic proteins (Hoppe 
et al., 2013; Hermans et al., 2014). For evaluation of the effect of in ovo immunization, we used GEM particles and neutral liposomes as carriers for Campylobacter antigens. To the best of our knowledge, liposomes, which have been studied as adjuvants or delivery system in many vaccine preparations, so far have not been tested for in ovo chicken immunization (Watson et al., 2012; Schwendener, 2014). The antigens can be chemically linked to the liposome surface, bound with the lipid bilayer by electrostatic or hydrophobic interactions, or encapsulated in the liposome water compartment (Taneichi et al., 2010). In our work, we observed a strong interaction between liposomes and the $\mathrm{rCjaAD}$ protein, resulting in nearly $100 \%$ protein accommodation in bilayer structure. The observed anti-rCjaAD activity indicates that the protein epitopes responsible for an immunological response are at least partially exposed to immunocompetent cells and confirms that the protein possesses hydrophobic domains that are able to incorporate in the lipid bilayer. In general, protein adsorption by electrostatic interaction or binding produces higher immunization than protein encapsulation within the liposomal interior. Since promising results have been achieved with liposomal vaccination by the $\mathrm{rCjaAD}$ protein, several different approaches can be proposed. For example, comparison of cationic, anionic and neutral liposomes will explore the importance of charge on the immunization process. Also, incorporation of extra adjuvants like monophosporyl lipid A or alluminia salts may lead to a more complex immunological response that offers a longer lasting effect. Both vaccine prototypes were introduced into the embryo amniotic sac at day 18 of embryonation, when the chicken embryo immune system is capable of responding to administered antigen. The process should induce the gut-associated lymphoid tissues (Negash et al., 2004). Preliminary data on the level of specific antirCjaAD intestinal IgA confirm some gut-associated lymphoid induction. In the in ovo vaccination experiments, commercial broiler Rosa chicks were employed. The level of their intestinal track colonization was higher than those previously described by us and others. Why the commercial broiler Rosa chickens are so susceptible to Campylobacter colonization remains unclear. However, regardless of the employed carrier, in ovo immunization resulted in significant reduction of colonization. The median reduction in C. jejuni cecal contents was about 1.0 $\log _{10}$ for in ovo immunization with GEM particles containing rCjaAD and about $2 \log _{10}$ for in ovo immunization with liposomes containing $\mathrm{rCjaAD}$. The observed differences between the reduction of colonization achieved by vaccination with the two vectors (GEMs vs. liposomes) may suggest that liposomes are more efficiently taken in by APC cells. Additionally, as demonstrated, $\mathrm{rCjaAD}$ antigen intercalates into the lipid bilayer of the liposomes, and this may protect it from degradation. More experiments are needed to evaluate the reduction of the level of chicken colonization by Campylobacter by a liposome-based vaccine formulation when lower Campylobacter doses are used for challenge.

Overall, the presented data shows that it is worthwhile to explore the efficiency of using a subunit vaccine composed of Campylobacter recombinant hybrid protein delivered by non-live vectors and an in ovo route of vaccination to combat bird colonization by Campylobacter. However, it should be emphasized that routes of immunization using GEM particles as a vehicles cannot be directly compared as various chickens' lines were used in these two sets of experiments. Nevertheless, in ovo vaccination posses some advantages over other routes of immunization. Firstly, it is more relevant for practical use by the poultry industry. Secondly, there are several strategies that allow incorporation of extra adjuvant molecules into the liposome, which may help modulate the strength and the type of immune response. Moreover, in ovo vaccination may be additionally combined with post-hatch boosting using live Lactobacillus isolated from the chicken gastrointestinal tract or attenuated Salmonella strains as delivery vectors (Wyszyńska et al., 2004; Łaniewski et al., 2012). The effect of in ovo immunization may be also intensified by blocking Campylobacter adhesion to avian mucin or by increasing activity of chicken's defensins (Struwe et al., 2015).

\section{AUTHOR CONTRIBUTIONS}

EJ-K, AKW and PAK conceived and designed the study. PAK, $\mathrm{AKW}, \mathrm{JG}, \mathrm{AW}, \mathrm{OW}$, and KD carried out the laboratory work. AKW, PAK, MK, RG, IA carried out animal experiment. EJ-K, PAK, and AKW analyzed the data. EJ-K, AKW, JG and PAK wrote the manuscript. All authors read and approved the final manuscript.

\section{FUNDING}

The work was supported by grants from the National Science Center, Poland (grants No 2011/03/B/NZ1/00592 and No UMO2012/07/B/NZ3/02919) and by the Ministry of Science and Higher Education through the Faculty of Biology, University of Warsaw intramural grant DSM 104910 and DSM 107421 and by the PARENT BRIDGE programme of the Foundation for Polish Science, cofinanced from the European Union under the European Regional Development Fund, POMOST/2012-6/4.

\section{ACKNOWLEDGMENTS}

We thank Dr J. Hansen for his critical reading of the manuscript.

\section{SUPPLEMENTARY MATERIAL}

The Supplementary Material for this article can be found online at: http://journal.frontiersin.org/article/10.3389/fmicb.2016. 00740

FIGURE S1 | Western blot analysis of the specificity of anti-LysM serum. Protein extracts purified by affinity chromatography were separated by $12 \%$ SDS-PAGE under reducing conditions and probed with anti-LysM antibodies. Lanes: 1 - 6xHis-LysM, 2 - 6xHis-CjaA-LysM; 3 - 6xHis-CjaD-LysM; M - protein molecular-weight marker. 


\section{FIGURE S2 | Western blot analysis of the specificity of}

6xHis-rCjaAD-LysM. Proteins were separated by $12 \%$ SDS-PAGE under reducing conditions and probed with: (A) anti-LysM, (B) anti-CjaA, and (C) anti-CjaD antibodies. Lanes: 1 - purified protein 6xHis-rCjaAD-LysM, M - protein molecular-weight marker.

\section{REFERENCES}

Agunos, A., Waddell, L., Leger, D., and Taboada, E. (2014). A systematic review characterizing on-farm sources of Campylobacter spp. for broiler chickens. PLoS ONE 9:e104905. doi: 10.1371/journal.pone.0104905

Alfredson, D. A., and Korolik, V. (2007). Antibiotic resistance and resistance mechanisms in Campylobacter jejuni and Campylobacter coli. FEMS Microbiol. Lett. 277, 123-132. doi: 10.1111/j.1574-6968.2007.00935.x

Annamalai, T., Pina-Mimbela, R., Kumar, A., Binjawadagi, B., Liu, Z., Renukaradhya, G. J., et al. (2013). Evaluation of nanoparticle-encapsulated outer membrane proteins for the control of Campylobacter jejuni colonization in chickens. Poult. Sci. 92, 2201-2211. doi: 10.3382/ps.2012-03004

Awad, W. A., Aschenbach, J. R., Ghareeb, K., Khayal, B., Hess, C., and Hess, M. (2014). Campylobacter jejuni influences the expression of nutrient transporter genes in the intestine of chickens. Vet. Microbiol. 172, 195-201. doi: 10.1016/j.vetmic.2014.04.001

Awad, W. A., Molnar, A., Aschenbach, J. R., Ghareeb, K., Khayal, B., Hess, C., et al. (2015a). Campylobacter infection in chickens modulates the intestinal epithelial barrier function. Innate Immun. 21, 151-160. doi: 10.1177/1753425914521648

Awad, W. A., Smorodchenko, A., Hess, C., Aschenbach, J. R., Molnar, A., Dublecz, K., et al. (2015b). Increased intracellular calcium level and impaired nutrient absorption are important pathogenicity traits in the chicken intestinal epithelium during Campylobacter jejuni colonization. Appl. Microbiol. Biotechnol. 99, 6431-6441. doi: 10.1007/s00253-015-6543-z

Backert, S., Boehm, M., Wessler, S., and Tegtmeyer, N. (2013). Transmigration route of Campylobacter jejuni across polarized intestinal epithelial cells: paracellular, transcellular or both? Cell Commun. Signal. 11:72. doi: 10.1186/1478-811X-11-72

Bande, F., Arshad, S. S., Bejo, M. H., Moeini, H., and Omar, A. R. (2015). Progress and challenges toward the development of vaccines against avian infectious bronchitis. J. Immunol. Res. 2015:424860. doi: 10.1155/2015/424860

Bosma, T., Kanninga, R., Neef, J., Audouy, S. A., van Roosmalen, M. L., Steen, A., et al. (2006). Novel surface display system for proteins on non-genetically modified gram-positive bacteria. Appl. Environ. Microbiol. 72, 880-889. doi: 10.1128/AEM.72.1.880-889.2006

Bouwman, L. I., Niewold, P., and van Putten, J. P. (2013). Basolateral invasion and trafficking of Campylobacter jejuni in polarized epithelial cells. PLoS ONE 8:e54759. doi: 10.1371/journal.pone.0054759

Buckley, A. M., Wang, J., Hudson, D. L., Grant, A. J., Jones, M. A., Maskell, D. J., et al. (2010). Evaluation of live-attenuated Salmonella vaccines expressing Campylobacter antigens for control of C. jejuni in poultry. Vaccine 28, 10941105. doi: 10.1016/j.vaccine.2009.10.018

Byrne, C. M., Clyne, M., and Bourke, B. (2007). Campylobacter jejuni adhere to and invade chicken intestinal epithelial cells in vitro. Microbiology 153, 561-569. doi: 10.1099/mic.0.2006/000711-710

Chintoan-Uta, C., Cassady-Cain, R. L., Al-Haideri, H., Watson, E., Kelly, D. J., Smith, D. G., et al. (2015). Superoxide dismutase SodB is a protective antigen against Campylobacter jejuni colonisation in chickens. Vaccine 33, 6206-6211. doi: 10.1016/j.vaccine.2015.09.100

Clark, J. D., Oakes, R. D., Redhead, K., Crouch, C. F., Francis, M. J., Tomley, F. M., et al. (2012). Eimeria species parasites as novel vaccine delivery vectors: antiCampylobacter jejuni protective immunity induced by Eimeria tenella-delivered CjaA. Vaccine 30, 2683-2688. doi: 10.1016/j.vaccine.2012.02.002

Cuccui, J., Thomas, R. M., Moule, M. G., D’Elia, R. V., Laws, T. R., Mills, D. C., et al. (2013). Exploitation of bacterial N-linked glycosylation to develop a novel recombinant glycoconjugate vaccine against Francisella tularensis. Open. Biol. 3:130002. doi: 10.1098/rsob.130002

Davis, S., Feikin, D., and Johnson, H. L. (2013). The effect of Haemophilus influenzae type $\mathrm{B}$ and pneumococcal conjugate vaccines on childhood meningitis mortality: a systematic review. BMC Public Health 13(Suppl. 3):S21. doi: 10.1186/1471-2458-13-S3-S21
FIGURE S3 | Localization of rCjaADLysM fusion protein on TCA-

pretreated $\boldsymbol{L}$. salivarius. Fusion protein were visualized with anti-rCjaAD antibodies that were further detected with goat anti-rabbit IgG Alexa Fluor A488. Fluorescence was visualized with a NIKON A1R MP microscope. The bar represents $2 \mu \mathrm{m}$

EFSA and ECDC (2014). The european union summary report on trends and sources of zoonoses, zoonotic agents and foodborne outbreaks in 2012. EFSA J. 12:3547. doi: 10.2903/j.efsa.2014.3547

EFSA and ECDC (2015). The european union summary report on trends and sources of zoonoses, zoonotic agents and food -borne outbreaks in 2013. EFSA J. 13:3991. doi: 10.2903/j.efsa.2015.3991

Gibreel, A., and Taylor, D. E. (2006). Macrolide resistance in Campylobacter jejuni and Campylobacter coli. J. Antimicrob. Chemother. 58, 243-255. doi: $10.1093 / \mathrm{jac} / \mathrm{dkl} 210$

Goldblatt, D. (2000). Conjugate vaccines. Clin. Exp. Immunol. 119, 1-3.

Guerry, P., Poly, F., Riddle, M., Maue, A. C., Chen, Y. H., and Monteiro, M. A. (2012). Campylobacter polysaccharide capsules: virulence and vaccines. Front. Cell Infect. Microbiol. 2:7. doi: 10.3389/fcimb.2012.00007

Hermans, D., Pasmans, F., Messens, W., Martel, A., Van Immerseel, F., Rasschaert, G., et al. (2012). Poultry as a host for the zoonotic pathogen Campylobacter jejuni. Vector Borne Zoonot. Dis. 12, 89-98. doi: $10.1089 /$ vbz.2011.0676

Hermans, D., Van Steendam, K., Verbrugghe, E., Verlinden, M., Martel, A., Seliwiorstow, T., et al. (2014). Passive immunization to reduce Campylobacter jejuni colonization and transmission in broiler chickens. Vet. Res. 45:27. doi: 10.1186/1297-9716-45-27

Hodgins, D. C., Barjesteh, N., St Paul, M., Ma, Z., Monteiro, M. A., and Sharif, S. (2015). Evaluation of a polysaccharide conjugate vaccine to reduce colonization by Campylobacter jejuni in broiler chickens. BMC Res. 8:204. doi: 10.1186/s13104-015-1203-Z

Hoppe, S., Bier, F. F., and von Nickisch-Rosenegk, M. (2012). Microarraybased method for screening of immunogenic proteins from bacteria. J. Nanobiotechnol. 10:12. doi: 10.1186/1477-3155-10-12

Hoppe, S., Bier, F. F., and von Nickisch-Rosenegk, M. (2013). Rapid identification of novel immunodominant proteins and characterization of a specific linear epitope of Campylobacter jejuni. PLoS ONE 8:e65837. doi: 10.1371/journal.pone.0065837

Hoppe, S., Bier, F. F., and von Nickisch-Rosenegk, M. (2014). Identification of antigenic proteins of the nosocomial pathogen Klebsiella pneumoniae. PLoS ONE 9:e110703. doi: 10.1371/journal.pone.0110703

Huang, J. L., Yin, Y. X., Pan, Z. M., Zhang, G., Zhu, A. P., Liu, X. F., et al. (2010). Intranasal immunization with chitosan/pCAGGS-flaA nanoparticles inhibits Campylobacter jejuni in a White Leghorn model. J. Biomed. Biotechnol. 2010:589476. doi: 10.1155/2010/589476

Humphrey, S., Chaloner, G., Kemmett, K., Davidson, N., Williams, N., Kipar, A., et al. (2014). Campylobacter jejuni is not merely a commensal in commercial broiler chickens and affects bird welfare. MBio 5:e01364. doi: 10.1128/mBio.01364-1314

Ihssen, J., Kowarik, M., Dilettoso, S., Tanner, C., Wacker, M., and Thony-Meyer, L. (2010). Production of glycoprotein vaccines in Escherichia coli. Microb Cell Fact. 9:61. doi: 10.1186/1475-2859-9-61

Indikova, I., Humphrey, T. J., and Hilbert, F. (2015). Survival with a helping hand: Campylobacter and microbiota. Front. Microbiol. 6:1266. doi: 10.3389/fmicb.2015.01266

Kaakoush, N. O., Castano-Rodriguez, N., Mitchell, H. M., and Man, S. M. (2015). Global epidemiology of Campylobacter infection. Clin. Microbiol. Rev. 28, 687-720. doi: 10.1128/CMR.00006-15

Katsma, W. E., De Koeijer, A. A., Jacobs-Reitsma, W. F., Mangen, M. J., and Wagenaar, J. A. (2007). Assessing interventions to reduce the risk of Campylobacter prevalence in broilers. Risk Anal. 27, 863-876. doi: 10.1111/j.1539-6924.2007.00928.x

Keestra, A. M., de Zoete, M. R., Bouwman, L. I., Vaezirad, M. M., and van Putten, J. P. (2013). Unique features of chicken Toll-like receptors. Dev. Comp. Immunol. 41, 316-323. doi: 10.1016/j.dci.2013.04.009

Kobierecka, P., Wyszyńska, A., Maruszewska, M., Wojtania, A., Zylinska, J., Bardowski, J., et al. (2015). Lactic acid bacteria as a surface display platform 
for Campylobacter jejuni antigens. J. Mol. Microbiol. Biotechnol. 25, 1-10. doi: $10.1159 / 000368780$

Kobierecka, P. A., Olech, B., Książek, M., Derlatka, K., Adamska, I., Majewski, P. M., et al. (2016). Cell wall anchoring of the Campylobacter antigens to Lactococcus lactis. Front. Microbiol. 7:165. doi: 10.3389/fmicb.2016.00165

Larson, C. L., Shah, D. H., Dhillon, A. S., Call, D. R., Ahn, S., Haldorson, G. J., et al. (2008). Campylobacter jejuni invade chicken LMH cells inefficiently and stimulate differential expression of the chicken CXCLi1 and CXCLi2 cytokines. Microbiology 154, 3835-3847. doi: 10.1099/mic.0.2008/021279-21270

Layton, S. L., Morgan, M. J., Cole, K., Kwon, Y. M., Donoghue, D. J., Hargis, B. M., et al. (2011). Evaluation of Salmonella-vectored Campylobacter peptide epitopes for reduction of Campylobacter jejuni in broiler chickens. Clin. Vaccine Immunol. 18, 449-454. doi: 10.1128/CVI.00379-310

Łaniewski, P., Kuczkowski, M., Chrzastek, K., Wozniak, A., Wyszyńska, A., Wieliczko, A., et al. (2014). Evaluation of the immunogenicity of Campylobacter jejuni CjaA protein delivered by Salmonella enterica sv. Typhimurium strain with regulated delayed attenuation in chickens. World J. Microbiol. Biotechnol. 30, 281-292. doi: 10.1007/s11274-013-1447-1445

Łaniewski, P., Lis, M., Wyszyńska, A., Majewski, P., Godlewska, R., and JagusztynKrynicka, E. K. (2012). Assessment of chicken protection against Campylobacter jejuni infection by immunization with avirulent Salmonella enterica sv. Typhimurium strain producing Campylobacter $\mathrm{CjaD} / \mathrm{Pal}$ protein. Vaccine 2, 43-50. doi: 10.2147/VDT.S33742

Maue, A. C., Poly, F., and Guerry, P. (2014). A capsule conjugate vaccine approach to prevent diarrheal disease caused by Campylobacter jejuni. Hum. Vaccin. Immunother. 10, 1499-1504. doi: 10.4161/hv.27985

Naughton, J., Duggan, G., Bourke, B., and Clyne, M. (2014). Interaction of microbes with mucus and mucins: recent developments. Gut Microbes 5, 48-52. doi: $10.4161 /$ gmic. 26680

Naughton, J. A., Marino, K., Dolan, B., Reid, C., Gough, R., Gallagher, M. E., et al. (2013). Divergent mechanisms of interaction of Helicobacter pylori and Campylobacter jejuni with mucus and mucins. Infect. Immun. 81, 2838-2850. doi: 10.1128/IAI.00415-413

Neal-McKinney, J. M., Samuelson, D. R., Eucker, T. P., Nissen, M. S., Crespo, R., and Konkel, M. E. (2014). Reducing Campylobacter jejuni colonization of poultry via vaccination. PLOS ONE 9:e114254. doi: 10.1371/journal.pone.0114254

Negash, T., al-Garib, S. O., and Gruys, E. (2004). Comparison of in ovo and post-hatch vaccination with particular reference to infectious bursal disease. A review. Vet. Q. 26, 76-87. doi: 10.1080/01652176.2004.9695170

Newell, D. G., Elvers, K. T., Dopfer, D., Hansson, I., Jones, P., James, S., et al. (2011). Biosecurity-based interventions and strategies to reduce Campylobacter spp. on poultry farms. Appl. Environ. Microbiol. 77, 8605-8614. doi: 10.1128/AEM.01090-1010

Nielsen, L. N., Luijkx, T. A., Vegge, C. S., Johnsen, C. K., Nuijten, P., Wren, B. W., et al. (2012). Identification of immunogenic and virulence-associated Campylobacter jejuni proteins. Clin. Vaccine Immunol. 19, 113-119. doi: 10.1128/CVI.05161-5111

Noor, S. M., Husband, A. J., and Widders, P. R. (1995). In ovo oral vaccination with Campylobacter jejuni establishes early development of intestinal immunity in chickens. Br. Poult. Sci. 36, 563-573. doi: 10.1080/00071669508 417802

Oh, E., and Jeon, B. (2015). Synergistic anti-Campylobacter jejuni activity of fluoroquinolone and macrolide antibiotics with phenolic compounds. Front. Microbiol. 6:1129. doi: 10.3389/fmicb.2015.01129

Pace, D., Pollard, A. J., and Messonier, N. E. (2009). Quadrivalent meningococcal conjugate vaccines. Vaccine 27(Suppl. 2), B30-B41. doi: 10.1016/j.vaccine.2009.05.003

Pan, D., and Yu, Z. (2014). Intestinal microbiome of poultry and its interaction with host and diet. Gut Microbes 5, 108-119. doi: 10.4161/gmic.26945

Pawelec, D. P., Korsak, D., Wyszyńska, A. K., Rozynek, E., Popowski, J., and Jagusztyn-Krynicka, E. K. (2000). Genetic diversity of the Campylobacter genes coding immunodominant proteins. FEMS Microbiol. Lett. 185, 43-49.

Ramasamy, R., Yasawardena, S., Zomer, A., Venema, G., Kok, J., and Leenhouts, K. (2006). Immunogenicity of a malaria parasite antigen displayed by Lactococcus lactis in oral immunisations. Vaccine 24, 3900-3908. doi: 10.1016/j.vaccine.2006.02.040
Robyn, J., Rasschaert, G., Pasmans, F., and Heyndrickx, M. (2015). Thermotolerant Campylobacter during broiler rearing: risk factors and intervention. Compreh. Rev. Food Sci. Food Saf. 14, 81-105. doi: 10.1111/1541-4337.12124

Rubin, C. J., Zody, M. C., Eriksson, J., Meadows, J. R., Sherwood, E., Webster, M. T., et al. (2010). Whole-genome resequencing reveals loci under selection during chicken domestication. Nature 464, 587-591. doi: 10.1038/nature08832

Sahin, O., Zhang, Q., Meitzler, J. C., Harr, B. S., Morishita, T. Y., and Mohan, R. (2001). Prevalence, antigenic specificity, and bactericidal activity of poultry anti-Campylobacter maternal antibodies. Appl. Environ. Microbiol. 67, 39513957.

Sambrook, J., and Russel, D. W. (2001). Molecular Cloning - A Laboratory Manual, 3th Edn. New York, NY: Cold Spring Harbor Laboratory Press.

Schokker, D., Veninga, G., Vastenhouw, S. A., Bossers, A., de Bree, F. M., KaalLansbergen, L. M., et al. (2015). Early life microbial colonization of the gut and intestinal development differ between genetically divergent broiler lines. BMC Genomics 16:418. doi: 10.1186/s12864-015-1646-1646

Schwendener, R. A. (2014). Liposomes as vaccine delivery systems: a review of the recent advances. Ther. Adv. Vaccines 2, 159-182. doi: $10.1177 / 2051013614541440$

Shoaf-Sweeney, K. D., Larson, C. L., Tang, X., and Konkel, M. E. (2008). Identification of Campylobacter jejuni proteins recognized by maternal antibodies of chickens. Appl. Environ. Microbiol. 74, 6867-6875. doi: 10.1128/AEM.01097-1098

Stewart, J. C. (1980). Colorimetric determination of phospholipids with ammonium ferrothiocyanate. Anal. Biochem. 104, 10-14.

Struwe, W. B., Gough, R., Gallagher, M. E., Kenny, D. T., Carrington, S. D., Karlsson, N. G., et al. (2015). Identification of O-glycan Structures from chicken intestinal mucins provides insight into Campylobactor jejuni pathogenicity. Mol. Cell. Proteomics 14, 1464-1477. doi: 10.1074/mcp.M114. 044867

Studier, F. W. (2005). Protein production by auto-induction in high density shaking cultures. Protein Expr. Purif. 41, 207-234.

Szymanski, C. M., and Wren, B. W. (2005). Protein glycosylation in bacterial mucosal pathogens. Nat. Rev. Microbiol. 3, 225-237. doi: 10.1038/nrmicro1100

Taneichi, M., Tanaka, Y., Kakiuchi, T., and Uchida, T. (2010). Liposome-coupled peptides induce long-lived memory CD8 T cells without CD4 T cells. PLoS ONE 5:e15091. doi: 10.1371/journal.pone.0015091

Terra, V. S., Mills, D. C., Yates, L. E., Abouelhadid, S., Cuccui, J., and Wren, B. W. (2012). Recent developments in bacterial protein glycan coupling technology and glycoconjugate vaccine design. J. Med. Microbiol. 61, 919-926. doi: 10.1099/jmm.0.039438-39430

Theoret, J. R., Cooper, K. K., Zekarias, B., Roland, K. L., Law, B. F., Curtiss, R. III. et al. (2012). The Campylobacter jejuni Dps homologue is important for in vitro biofilm formation and cecal colonization of poultry and may serve as a protective antigen for vaccination. Clin. Vaccine Immunol. 19, 1426-1431. doi: 10.1128/CVI.00151-112

Toro, H., Tang, D. C., Suarez, D. L., Sylte, M. J., Pfeiffer, J., and Van Kampen, K. R. (2007). Protective avian influenza in ovo vaccination with non-replicating human adenovirus vector. Vaccine 25, 2886-2891. doi: 10.1016/j.vaccine.2006.09.047

Trotter, C. L., McVernon, J., Ramsay, M. E., Whitney, C. G., Mulholland, E. K., Goldblatt, D., et al. (2008). Optimising the use of conjugate vaccines to prevent disease caused by Haemophilus influenzae type b, Neisseria meningitidis and Streptococcus pneumoniae. Vaccine 26, 4434-4445. doi: 10.1016/j.vaccine.2008.05.073

van Dijk, A., Veldhuizen, E. J., Kalkhove, S. I., Tjeerdsma-van Bokhoven, J. L., Romijn, R. A., and Haagsman, H. P. (2007). The beta-defensin gallinacin6 is expressed in the chicken digestive tract and has antimicrobial activity against food-borne pathogens. Antimicrob. Agents Chemother. 51, 912-922. doi: 10.1128/AAC.00568-566

Wagenaar, J. A., French, N. P., and Havelaar, A. H. (2013). Preventing Campylobacter at the source: why is it so difficult? Clin. Infect. Dis. 57, 16001606. doi: $10.1093 / \mathrm{cid} / \mathrm{cit} 555$

Watson, D. S., Endsley, A. N., and Huang, L. (2012). Design considerations for liposomal vaccines: influence of formulation parameters on antibody and cell-mediated immune responses to liposome associated antigens. Vaccine 30, 2256-2272. doi: 10.1016/j.vaccine.2012.01.070 
Watson, R. O., and Galan, J. E. (2008). Campylobacter jejuni survives within epithelial cells by avoiding delivery to lysosomes. PLoS Pathog. 4:e14. doi: 10.1371/journal.ppat.0040014

Weil-Olivier, C., van der Linden, M., de Schutter, I., Dagan, R., and Mantovani, L. (2012). Prevention of pneumococcal diseases in the post-seven valent vaccine era: a European perspective. BMC Infect. Dis. 12:207. doi: 10.1186/1471-233412-207

Wigley, P. (2013). Immunity to bacterial infection in the chicken. Dev. Comp. Immunol. 41, 413-417. doi: 10.1016/j.dci.2013.04.008

Wyszyńska, A., Raczko, A., Lis, M., and Jagusztyn-Krynicka, E. K. (2004). Oral immunization of chickens with avirulent Salmonella vaccine strain carrying $C$. jejuni 72Dz/92 cjaA gene elicits specific humoral immune response associated with protection against challenge with wild-type Campylobacter. Vaccine 22, 1379-1389. doi: 10.1016/j.vaccine.2003.11.001

Yeoman, C. J., Chia, N., Jeraldo, P., Sipos, M., Goldenfeld, N. D., and White, B. A. (2012). The microbiome of the chicken gastrointestinal tract. Anim. Health Res. Rev. 13, 89-99. doi: 10.1017/S1466252312000138

Zambrano, L. D., Levy, K., Menezes, N. P., and Freeman, M. C. (2014). Human diarrhea infections associated with domestic animal husbandry: a systematic review and meta-analysis. Trans. R. Soc. Trop. Med. Hyg. 108, 313-325. doi: $10.1093 /$ trstmh/tru056

Zeng, X., Xu, F., and Lin, J. (2010). Development and evaluation of CmeC subunit vaccine against Campylobacter jejuni. J. Vaccines Vaccin. 1:112. doi: $10.4172 / 2157-7560.1000112$

Conflict of Interest Statement: The authors declare that the research was conducted in the absence of any commercial or financial relationships that could be construed as a potential conflict of interest.

Copyright (C) 2016 Kobierecka, Wyszyńska, Gubernator, Kuczkowski, Wiśniewski, Maruszewska, Wojtania, Derlatka, Adamska, Godlewska and Jagusztyn-Krynicka. This is an open-access article distributed under the terms of the Creative Commons Attribution License (CC BY). The use, distribution or reproduction in other forums is permitted, provided the original author(s) or licensor are credited and that the original publication in this journal is cited, in accordance with accepted academic practice. No use, distribution or reproduction is permitted which does not comply with these terms. 